\title{
Effectiveness of SCRUM in Project Based Learning: Students View
}

\author{
José Dinis-Carvalho, Ana Ferreira, Catarina Barbosa, Cláudia Lopes, Helena Macedo, \\ Paulo Tereso \\ Production and Systems Department, University of Minho, Portugal \\ dinis@dps.uminho.pt, anaf3ferreira@gmail.com, catarina.cacote@gmail.com, clau- \\ dia.lopes822@gmail.com, helena_macedo@outlook.com, \\ paulo151295@gmail.com
}

\begin{abstract}
Project and team management play a major role in the student teams' projects performance. This is more evident when the projects last long time and the teams are large. In this work a student team accepted to use SCRUM as their project management methodology during their Project Based Learning (PjBL) experience. This PjBL experience took place on the $7^{\text {th }}$ semester of the Integrated Master in Industrial Engineering and Management degree. The team had a short period training on the technique and then applied it throughout the entire semester. Although not very enthusiastic in the beginning of the project the team gradually became aware on the advantages of SCRUM features recognizing the feeling of having the project under control and gaining management effectiveness throughout the semester. At the end the team performed well above the average being one of the two teams with the highest score of the class.
\end{abstract}

Keywords: Project Based Learning; SCRUM; Project Management

\section{Introduction}

Project Based Learning (PjBL) (Dym, Agogino, Eris, Frey, \& Leifer, 2005) can be a very worthy experience for students especially when the projects take place in real context. One of the complex issues of those experiences is the way that student teams manage themselves and manage their projects. A very typical problem is that student teams end up having most of the work taking place just few days before the milestones (due dates defined for deliverables such as presentations and reports). The quality of the deliverables could be better and student anxiety and stress could be reduced if student teams managed their work in more effective ways. The nature of these projects held in real context, so complex and open, with unpredictable results, are virtually impossible to plan in reasonable detail, so traditional project management methodologies are not applicable.

The objective of this study is to apply the SCRUM methodology as the project management and team management tool in a student team on a PjBL environment and evaluate its effectiveness.

adfa, p. 1, 2011.

(C) Springer-Verlag Berlin Heidelberg 2011 
From the 6 student teams involved in the PjBL semester carrying out a project in industry a team was randomly selected to adopt the SCRUM methodology. The team went through a quick training in SCRUM, then they had to read material about the methodology and finally spent an afternoon with a SCRUM professional to get as much information as possible based on their difficulties. After this initial approach to the methodology the team members where interviewed about their expectations regarding the methodology effectiveness in their project and the same type of interview took place at the end of the semester.

\section{Framework}

The engineering practices requires the application of transversal competences or soft skills such as autonomy, leadership or interaction with others in interdisciplinary teams, negotiation or solving conflicts, communication in effective ways, as well as project management skills (UNESCO, 2010). It is also recognised that the development of engineering competences requires the application of technical knowledge in specific contexts linked to the professional practice. Some examples of learning processes closer to the professional experience in higher education have resulted primarily from practical training in final years of formation or even after the end of initial formation. However, it can be argued that following this approach, students may lose the possibility to develop these competences integrating academic technical knowledge with professional knowledge.

\subsection{Project Based Learning}

Project-based learning $(\mathrm{PjBL})$ is a student-centred learning method focused on the development of a project in a real professional context, in which teams of students solve an interdisciplinary problem, articulating theory and practice during the development of a project (Graaf \& Kolmos, 2007) (P. Powell \& Weenk, 2003). Other characteristics of Project-based learning can also be referred as being focused on the integration of several knowledge areas (including technical and transversal skills) for solving a problem linked to real situations, during a long period of time (e.g. a semester), resulting in a specific final result (Helle, Tynjälä, \& Olkinuora, 2006).

The students develop several competencies: Knowledge, Skills and Attitudes when they go through PjBL experience in real context (Lima, Dinis-Carvalho, Sousa, Arezes, \& Mesquita, 2017). Project based learning using real world problems and context is believed to motivate students to identify and apply research concepts and information.

In PjBL methodology followed in the Integrated Master degree in Industrial Engineering and Management at the University of Minho in Portugal, teams of students develop a project during a semester while having traditional supporting courses in classrooms (Lima, Dinis-Carvalho, Sousa, Alves, et al., 2017). The projects are designed so the students must use competences that are developed at the same time in supporting courses. This integration when well managed results in a very effective use of lecturers and effective learning. 


\subsection{SCRUM}

Agile methodologies were used to handle the challenges of managing complex projects during the development phase. In 1986, Hirotaka Takeuchi and Ikujiro Nonaka named SCRUM the new product development standard in auto and consumer product companies. SCRUM originally was formalized for software development projects, but it has been applied in any complex and innovative scope of work (SCRUM Alliance, 2016). In fact, ninety four percent of all organizations practice some form of Agile and SCRUM is one of the most popular method of Agile because 86,9\% of Agile SCRUM users observe increased profits (Grieser, 2016) . However, a study of Agile software development shows that only $3 \%$ of the existing scientific evidence on Agile software development focuses on SCRUM (Dybå \& Dingsøyr, 2008).

In the SCRUM process there are three important factors, which should be applied during the different project development phases: transparency (the process must be visible to everyone who is involved in the project), inspection (SCRUM users must inspect SCRUM artifacts frequently, such as the product backlog and the sprint backlog, to detect problems in early stages) and adaptation (if an inspector determines that some aspects of the project are unacceptable and outside of the project scope, the process can be adjusted to avoid further problems) (Sutherland \& Schwaber, 2017a). Furthermore, the objective of SCRUM is achieved by optimizing the development process by identifying the tasks, managing time more effectively, and setting-up teams.

The SCRUM team consists of a Product Owner, a SCRUM Master, and Development Team Members. The Product owner represents the business, customers or users, being responsible for managing the Product Backlog, the list of requirements of the product, which shows the functionality of the product from technical and business perspectives. He has also to ensure that the team understands the goals of the project and performs at a high level. The SCRUM Master instructs the Development Team on creating clear Product Backlog items and communicates with the team to ensure that the team understands the long-term plans of the project. The Development Team is responsible for implementing and delivering the releasable product at the end of each "Sprint," which is a period of time (referred to as a time-box) to create a usable increment of the product. Some items of the Product Backlog created by the SCRUM Master are selected for the specific sprint, and it is designated the Sprint Backlog. Each sprint can be considered as a one-month project with a plan of what needs to be built and how it needs to be built. The goals of each sprint are planned in the Sprint Planning Meeting, which occurs once a month prior to each sprint. Moreover, there is a daily SCRUM meeting where team members update one another on their progress, difficulties they have experienced and their future goals for the next meeting. Therefore, Sprints contain and consists of the Sprint Planning, Daily SCRUMs, the Sprint Review (where is discussed what each team member did during the product-development iteration) and the Sprint Retrospective (it is held to identify potential improvements for future sprints, based on performance of the last sprint in terms of human resources, communication and tools.). Hence, the Development team delivers products iteratively and incrementally, maximizing the feedback they receive. As the Development Team members, it has been found that the ideal size is seven members. They manage their own work and 
are self-organized, and are not grouped into sub-teams (Sutherland \& Schwaber, 2017b).

\subsection{EDUSCRUM}

The eduSCRUM was developed by Willy Wijnands, a professor of Physics and Chemistry at Ashram College located in the Netherlands. The eduSCRUM is nothing more than the SCRUM methodology applied to teaching, using the resources and activities of this framework in classroom work situations, and students receive an introductory training where you specify the various tools essential to the proper functioning of the eduSCRUM (Jager, 2015).

As SCRUM this methodology was developed to partial complex objectives in various tasks so that this way is achieved a continuous learning of the proposed study plans and also to organize the workload in order to minimize it, however, some students have difficulty mastering this method of work since only wonders what to do, but not how to do (Delhij, Solingen, \& Wijnands, 2015). The eduSCRUM teams, consisting of four students (team) and a teacher (Product Owner), and it is this aspect that this working method differs more typical SCRUM framework since the eduSCRUM Master will be elected the team students who will be the leader of the whole.

Meetings include Sprint where there is an initial planning, team building and the definition of the tasks to be performed. Later will be spent five minutes at the beginning of each class in order to synchronize and monitor tasks that are running and planning until the next meeting, this activity is given the name of Stand-up. Teams of students will show what they have learned and have achieved in the last Sprint also known as Sprint Review, latter Sprint should be taken into consideration if all the work by students going against the learning objectives and the goal proposed by the manner of presentation must differ between teams. In Sprints retrospective goal is more focused on developing interpersonal relationships in order to improve relations and develop improvements on a personal level (Jager, 2015).

As regards the tools used by eduSCRUM have the Flip, a frame A3 which allows an overview of the tasks to be accomplished during the Sprint. Part of the picture is devoted to the Product Backlog, this fraction is indispensable since it has a list of activities for the course of the entire project directed by the teacher, which is the Product Owner. This tool turns out to be essential also in the organization since it allows you to check the tasks done and make more directly the smooth functioning of this system involves updating the same in all stand-up meetings. In order to improve the SCRUM efficiency, the adaptation of this method should be followed by the tool Burndown Chart.

\section{Description of the PjBL model}

The Project-bases Learning ( $\mathrm{PjBL})$ model adopted in this case is a methodology inspired by the proposed Project Led Education (PLE) model (P. Powell \& Weenk, 2003) which aims to solve interdisciplinary problems based on a real situation where learning 
is student centered (P. C. Powell, 2004). Throughout the project students are able to develop technical and soft skills with great impact on their learning effectiveness.

The project is carried out in teams, supported by a team of teaching staff responsible for the curricular units and for the tutoring of each team. The role of the teaching staff is to provide technical support to the project allowing its development based on the respective course content. The tutor's role is in monitoring the project's progress heading the team of students in the desired direction and helping them in project and team management. The tutor is the closest member of the teaching staff to the student team with greater ease of communication, suggesting sources of information and provide feedback on the project's progress.

At the University of Minho, this methodology is adopted in the seventh semester of the Integrated MSc in Industrial Engineering and Management. The projects have been developed in student teams of 9-11 members, in cooperation with a company where the main objective is to deal with a real situation to improve the core competencies for professional practice (Lima, Mesquita, \& Rocha, 2013). In this project, students must analyze the respective company production system and present well founded suggestions for improvements. In addition, students must integrate the 6 courses of direct support to the project (PSC - "Project Support Courses") as described in Table 1.

Table 1. PSC - "Project Support Courses"

\begin{tabular}{clc}
\hline Year 4 & ECTS \\
\hline S1 & Ergonomics & 5 \\
S1 & Integrated Production Management & 5 \\
S1 & Production Systems Organization II & 5 \\
S1 & Integrated Project in Industrial Engineering and Management II & 5 \\
S1 & Simulation & 5 \\
S1 & Information Systems for Production & 5 \\
\hline
\end{tabular}

The assessment of the project (PIEGI II) is based on 2 reports (70\%) and 3 presentations (30\%). Throughout the semester student teams also perform self-assessment and peer assessment with impact in the final individual grading. In order to improve the reliability of the project work the teaching staff developed a set of milestones to monitor all project teams as well as providing a formal platform for teams to share their finding and problems. Table 2 describes all milestones for the project.

Table 2. Project Milestones

\begin{tabular}{cl}
\hline Milestones & \multicolumn{1}{c}{ Requirements } \\
\hline M1 & Initial project session with the students \\
M2 & Fist visit to the company \\
M3 & Project charter \\
M4 & First formal presentation of the progress of the project (Characterization, prob- \\
& lems identification and development proposals) \\
\hline
\end{tabular}




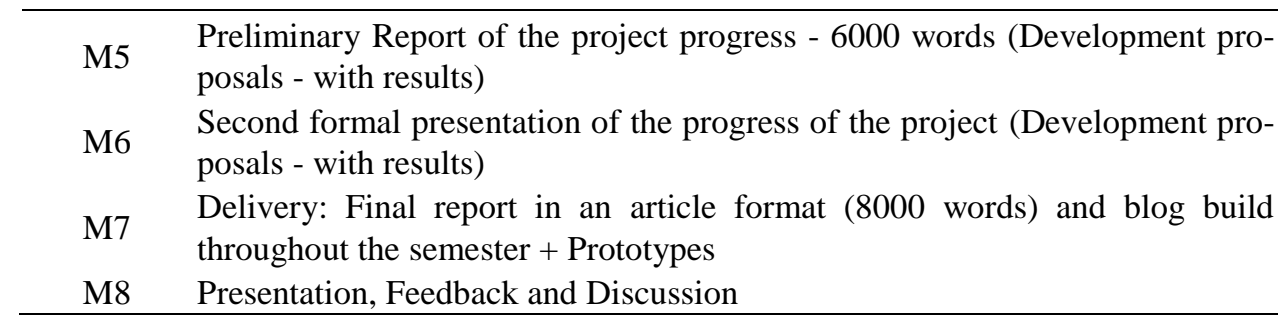

The main difficulties encountered by students during the course of this project are mostly related to interpersonal relations and project management. As for the interpersonal relationships, the main difficulties come for managing conflicts caused by differences of opinions, individual goals and the lack of communication within the group. The project management level, the challenges are focused on reconciliation schedules, deadlines greetings and planning organization of project tasks. Thus, it is necessary to apply project management methodologies in order to overcome these difficulties.

\section{$4 \quad$ SCRUM applied in a PjBL team}

In order to carry out the project it was felt the need to introduce a methodology able to plan and manage all the tasks to be performed in a quick and simple way. The need for a methodology of this kind stems from the fact that it is a very complex project, which in turn entails several tasks that need to be carried in time so that there is no accumulation of work that could result in future problems.

The initial training and reading material about SCRUM as well as the help from the tutor it was possible to understand the basics of the SCRUM methodology, until then unknown to all team members. After this initial phase dedicated to the understanding of SCRUM the student team built their own version of a SCRUM framework divided into four columns, Plans / Problems / Ideas, Portfolio Tasks, Sprint and Done. This framework can be seen on the left side of the team board depicted in figure 1. The use of team board placed in the team room space dedicated to the project as well as other visual management tools are encouraged by the teaching staff. Students are trained to experience the real advantages of visual management tools in their project and team management. 


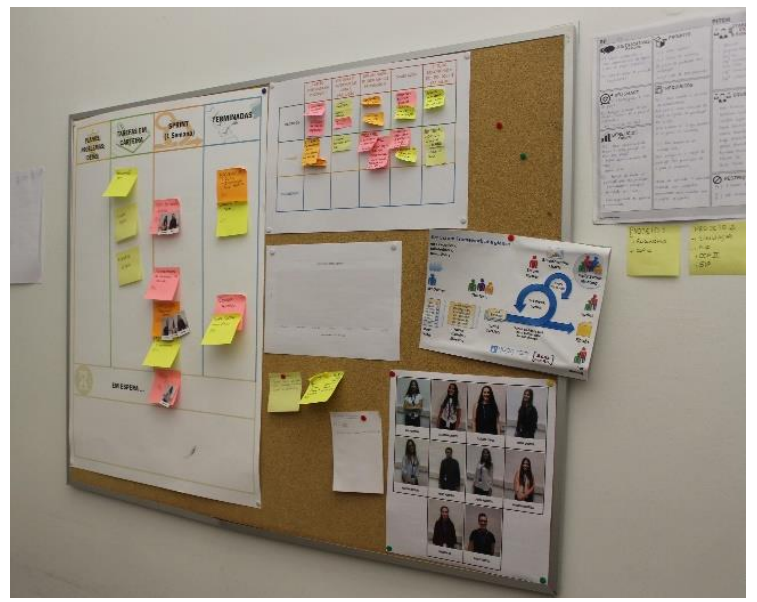

Figure 1. Students team main team.

In addition to these four columns, the SCRUM framework also includes a section devoted to waiting tasks, for assignments that were not completed on time or waiting from data from external entities. The team also adopted the burndown charts to monitor the progression of the completion of the planned sprint tasks with the average theoretical sprint pace. Figure 2 shows a team's burndown chart example for one sprint of one week. As can be observed the theoretical pace is represented by a straight line with the real progression is represented by the other set of line segments. This pattern was a typical pattern for all sprints because the team had less classes to attend to on Wednesdays so more work could be done on that day and more tasks were completed.

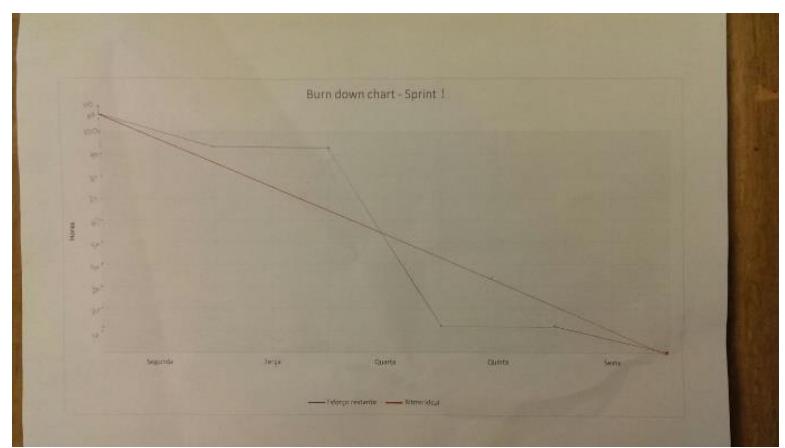

Figure 2. Example of a burndown Chart

The team decided to have the sprint review and sprint planning at the end of every Friday because no other time was possible to agenda restrictions. The first point of the meeting was the retrospective of the previous Sprint, having more emphasis to the column of completed and waiting tasks. Each element related what went worse and better throughout the week as well as some proposals improvement so the next week could be 
better. In this first point it is also finished the burndown chart, which allows the group know the number of hours worked and if it met the expectations.

The second meeting point was focuses on planning the next sprint for next week, an element is chosen every week, which will play the role of SCRUM Master. They are then planned all the necessary tasks to be performed, and are assigned to different elements as well as the number of hours corresponding to their achievement. With help of SCRUM Poker application with the Fibonacci sequence, each group member chooses a number that corresponds to the total of hours required to perform a given task. Subsequently ideas are discussed and long-term problems that will be placed in the first column above the SCRUM.

This meeting was one of the key points of this methodology when applied to PjBL as it allows the group to have a perception of the tasks performed, and thus it is possible to perceive the development state of the project and set tasks that require priority.

\section{$5 \quad$ Results}

The first contact with the SCRUM tool caused reluctance to all group members, since this approach never been displayed or used before. The lack of practice in the application of this method has a very long planning stage, due to the existence of different perceptions of the operation and concepts associated with SCRUM. However, the interest in the practice of new methods motivated the group to understand and improve their planning skills, organization and interaction through sharing ideas, research and group tutor support.

During the project, the group faced several difficulties in adapting to this tool. The long time spent in the sprints, the lack of understanding of the assignment of the number of hours devoted to each task and the lack of differentiation between "not started" tasks and task "sprint" were the main obstacles to overcome.

In order to fill these gaps, the team received additional support from the tutor and a workshop with a Product Owner (from a computer company) who clarified doubts and gave feedback on how SCRUM should be applied by the working team. After answering questions, the group honed his SCRUM techniques and the great advantages of this method began to show good results. Although it was necessary to spend a large amount of time in the weekly sprints, this very visual practice, proved fruitful in meeting deadlines, in performing each task as well as the assignment of responsibilities in the implementation of the same.

The use of the burndown chart graphic, to complement the way all this practice, proved to be an asset, since this tool is very visual and allows for easy perception of the amount of work performed by the group throughout the week. The results taken from these weekly charts show a large discrepancy compared with graphics related to the use of SCRUM methodology because is not applied in the field of education, since the work team only had the Wednesday and Friday to focus on achievement from the project. In the remaining days of the week the amount of work performed by group members was very low, reflecting only small individual work done outside of school. 
The SCRUM methodology when applied to PjBL provides the basis for a careful organization that enables easy management of all tasks, which in turn, results in an a more productive use of time. This can be said even when the SCRUM methodology was not being applied fully because of the environment condition of this study. Team member did not have proper training on the methodology neither the teaching staff had the necessary experience to assist them. The SCRUM master role was improvised by a team member without proper training and experience to perform that role in an effective way. The daily meetings to plan the day was not applied because the team had no agenda to do it. Finally the availability of team members to work was limited most of the days and varying frequently due to other academic duties.

\section{Conclusion}

The challenge that was faced in this work was to adopt the SCRUM methodology in a team of students under a Project Based Learning environment based on industrial problems to be solved. The project is the most important part of the semester in a way that failing the project represents a most certain failure in most other curricular units that support the project. The expectations and motivation are high among the students but the tension is high as well since every team wants to perform well and ideally better than other groups. It is difficult to put more variables in the game so student are normally against trying different methodologies for managing the project and the team. It happens that the randomly selected team although without enthusiasm and with a lot of doubts accepted to experiment the use of SCRUM.

The team started with many difficulties in accepting the amount of time spent in planning the sprints without seeing apparent benefit resulting from that effort. Gradually the team learned how to do it faster and more effective and felt the comfort of having everything under control and able to increase their speed from sprint to sprint. After the first four or five weeks the team was unable to manage themselves anymore without the SCRUM and its events and artifacts.

Even with the some limitations regarding the proper use of the SCRUM methodology at the end the team end up doing a lot of valuable work being one of the two teams with better score on the project and probably the adoption of the SCRUM methodology played a role on that success.

\section{$7 \quad$ Acknowledgements}

This work has been partially supported by projects COMPETE-POCI-01-0145FEDER-007043 and FCT-UID-CEC-00319-2013, from Portugal.

\section{$8 \quad$ References}

Delhij, A., Solingen, R. van, \& Wijnands, W. (2015). The eduScrum Guide. EduScrum Team. Dybå, T., \& Dingsøyr, T. (2008). Empirical studies of agile software development: A systematic 
review. Information and Software Technology, 50(9-10), 833-859. https://doi.org/10.1016/J.INFSOF.2008.01.006

Dym, C. L., Agogino, A. M., Eris, O., Frey, D. D., \& Leifer, L. J. (2005). Engineering design thinking, teaching, and learning. Journal of Engineering Design.

Graaf, E. de, \& Kolmos, A. (2007). Management of change: Implementation of problem-based and project-based learning in engineering. Roterdam: Sense Publishers.

Grieser, B. (2016). PMO advisory introduces SCRUM training courses in the metro New York. Retrieved January 1, 2018, from https://www.scrumalliance.org/why-scrum

Helle, L., Tynjälä, P., \& Olkinuora, E. (2006). Project-based learning in post-secondary education - Theory, practice and rubber sling shots. Higher Education. https://doi.org/10.1007/s10734-004-6386-5

Jager, T. de. (2015). Using eduScrum to introduce project-like features in Dutch secondary Computer Science Education. Utrecht University.

Lima, R. M., Dinis-Carvalho, J., Sousa, R. M., Alves, A. C., Moreira, F., Fernandes, S., \& Mesquita, D. (2017). Ten years of project-based learning (PBL) in industrial engineering and management at the University of Minho. PBL in Engineering Education: International Perspectives on Curriculum Change. https://doi.org/10.1007/978-94-6300-905-8

Lima, R. M., Dinis-Carvalho, J., Sousa, R. M., Arezes, P., \& Mesquita, D. (2017). Development of competences while solving real industrial interdisciplinary problems: A successful cooperation with industry. Producao, 27(Specialissue). https://doi.org/10.1590/01036513.230016

Lima, R. M., Mesquita, D., \& Rocha, C. (2013). Professionals' demands for Production Engineering: Analysing areas of professional practice and transversal competences. In 22nd International Conference on Production Research, ICPR 2013.

Powell, P. C. (2004). Assessment of team-based projects in project-led education. European Journal of Engineering Education, 29(2), 221-230. https://doi.org/10.1080/03043790310001633205

Powell, P., \& Weenk, W. (2003). Project-led engineering education. Utrecht: Lemma.

Scrum Alliance. (2016). Lear About Scrum. Retrieved January 1, 2018, from https://www.scrumalliance.org/why-scrum

Sutherland, J., \& Schwaber, K. (2017a). The Scrum Guide, the Definitive Guide to scrum: The Rules of the Game. Retrieved from https://www.scrumguides.org/scrum-guide.html

Sutherland, J., \& Schwaber, K. (2017b). The Scrum Guide, the Definitive Guide to scrum: The Rules of the Game.

UNESCO. (2010). UNESCO Engineering Report: Issues Challenges and Opportunities for Development. Paris: UNESCO Publishing. 